\title{
Qualitative evaluation of adherence therapy in Parkinson's disease: a multidirectional model
}

\author{
This article was published in the following Dove Press journal: \\ Patient Preference and Adherence \\ 10 July 2015 \\ Number of times this article has been viewed
}

\section{David James Daley ${ }^{1,2}$ Katherine Helen O'Leary \\ Deane $^{3}$ \\ Richard John Gray ${ }^{4}$ \\ Rebekah Hill ${ }^{3}$ \\ Phyo Kyaw Myint ${ }^{5}$}

'Norwich Medical School, Faculty of Medicine and Health Sciences, University of East Anglia, Norwich Research Park, ${ }^{2}$ Norfolk and Norwich University Hospital NHS Foundation Trust, ${ }^{3}$ School of Health Sciences, University of East Anglia, Norwich Research Park, Norwich, UK; ${ }^{4} \mathrm{Hamad}$ Medical Corporation, Doha, Qatar; ${ }^{5}$ Epidemiology Group, School of Medicine and Dentistry, Institute of Applied Health Sciences, College of Life Sciences and Medicine, University of Aberdeen, Aberdeen, UK
Correspondence: David James Daley Norwich Medical School, Faculty of Medicine and Health Sciences, University of East Anglia, Norwich, NR4 7TJ, UK Tel +44 I603 286 I43

Email d.daley@uea.ac.uk
Background: Medication can control the symptoms of Parkinson's disease (PD). Despite this, non-adherence with medication is prevalent in PD. Treatments for improving adherence with medication have been investigated in many chronic conditions, including PD. However, few researchers have evaluated their interventions qualitatively. We investigated the acceptability and potential mechanism of action of adherence therapy (AT) in PD patients and their spouse/ carers who received the intervention as part of a randomized controlled trial.

Methods: Sixteen participants (ten patients and six spouses/carers) who had recently completed the trial were purposely selected in order to cover a range of ages and disease severity. Semi-structured interviews were conducted in the participants' homes. Data were transcribed and analyzed using a thematic approach. A second researcher, naïve to PD and AT, analyzed the data independently to limit bias.

Results: The trial showed that AT significantly improved both medication adherence and quality of life in people with PD. Specifically, patients who received AT reported improvements in mobility, activities of daily living, emotional wellbeing, cognition, communication, and body discomfort. General beliefs about medication also significantly improved in those who received AT compared with controls. In the current qualitative evaluation, a total of 175 codes were generated, which formed eleven subthemes. These could be grouped under three overarching themes, ie, perceptions prior to AT, positive effects of AT, and attributes of AT.

Conclusion: This randomized controlled trial is the first to investigate AT in PD. The acceptability and underlying mechanism of the intervention suggest a new multidirectional model of AT in PD which future research should seek to confirm. The findings provide a deeper understanding of AT and will allow clinicians to modify the delivery of the intervention by acknowledging various pathways to improved outcomes.

Keywords: Parkinson's disease, medication, adherence therapy, acceptability, mechanisms

\section{Introduction}

Anti-parkinsonian medication can control the symptoms of Parkinson's disease (PD). Levodopa remains the most effective treatment, by replenishing dopaminergic tone in the nigrostriatal pathway. Monotherapy represents usual early phase management. However, more than half of PD patients take 2-4 anti-parkinsonian drugs 3-4 times daily. Advanced PD patients may be taking up to ten daily doses to manage fluctuations. It is therefore not surprising that non-adherence is prevalent in PD. ${ }^{1}$

In a systematic review, we identified factors (eg, depression and regimen complexity) associated with poor adherence in PD. ${ }^{2}$ Treatments for improving medication adherence in chronic conditions have been widely investigated, with complex behaviorally targeted interventions reported to be most beneficial. ${ }^{3,4}$ However, few studies have focused on PD. Through a randomized controlled trial (RCT; ISRCTN07830951), ${ }^{5}$ we recently reported the efficacy of a novel intervention, ie, adherence therapy (AT), 
in PD. ${ }^{6}$ AT significantly improved adherence compared with routine care (odds ratio 8.2; 95\% confidence interval [CI] 2.8-24.3). Compared with routine care, AT also significantly improved quality of life $(-9.0 ; 95 \% \mathrm{CI}-12.2,-5.8)$.

Although the effectiveness of adherence-enhancing strategies has been reported, few researchers have evaluated their interventions qualitatively. This is in terms of the underlying mechanism and the acceptability of the intervention from the perspective of patients. As a consequence, the mechanistic action of many adherence-enhancing strategies remains largely theoretical.

The aim of this qualitative explorative study was to investigate the experience of $\mathrm{PD}$ patients who received seven weekly sessions of AT as part of an RCT. ${ }^{6}$ Specifically, we were interested in patient acceptability, but we also aimed to explore potential mechanisms of action of AT in PD.

\section{Materials and methods}

\section{Design and participants}

Qualitative semi-structured interviews were undertaken with purposely selected participants (patients and spouse/ carers). Participants who had completed a program of AT were selected by the trial steering committee to capture a range of ages and disease severity.

\section{Adherence therapy}

AT is a cognitive-behavioral approach rooted in the observation that patient beliefs impact on adherence. The central theory is that when patients and professionals make choices collaboratively, patients are more likely to continue with those choices because they are personally owned and meaningful. ${ }^{7-9}$ Identification and amplification of the personally relevant benefits of treatment, modifying beliefs about medication, and exploring ambivalence toward taking medication are key components.

AT is delivered in five phases (Figure 1). Key skills include exchanging information (eg, explaining fluctuating drug concentrations through graphical representation), identifying inconsistencies between the patient's thoughts and behaviors about medication, Socratic-style questioning, and working with resistance to discussing medication and treatment. Ethical approval was obtained from the Cambridge central research ethics committee (11/EE/0179).

\section{Procedure and data generation}

After completing seven AT sessions, DJD (who delivered AT as part of a $\mathrm{PhD}$ project) provided participants with an information sheet about the qualitative study. Interested participants were visited at home 1 week later to complete the consent procedures. Audio-recorded interviews were conducted by DJD in the participants' homes to the point of saturation. Interviews were completed prior to RCT data analysis. Each interview explored the following broad topics: components of AT; communication style and therapy environment; participants' perception of AT; and what participants learned. The interview question prompts agreed by the trial steering committee are presented in Figure S1.

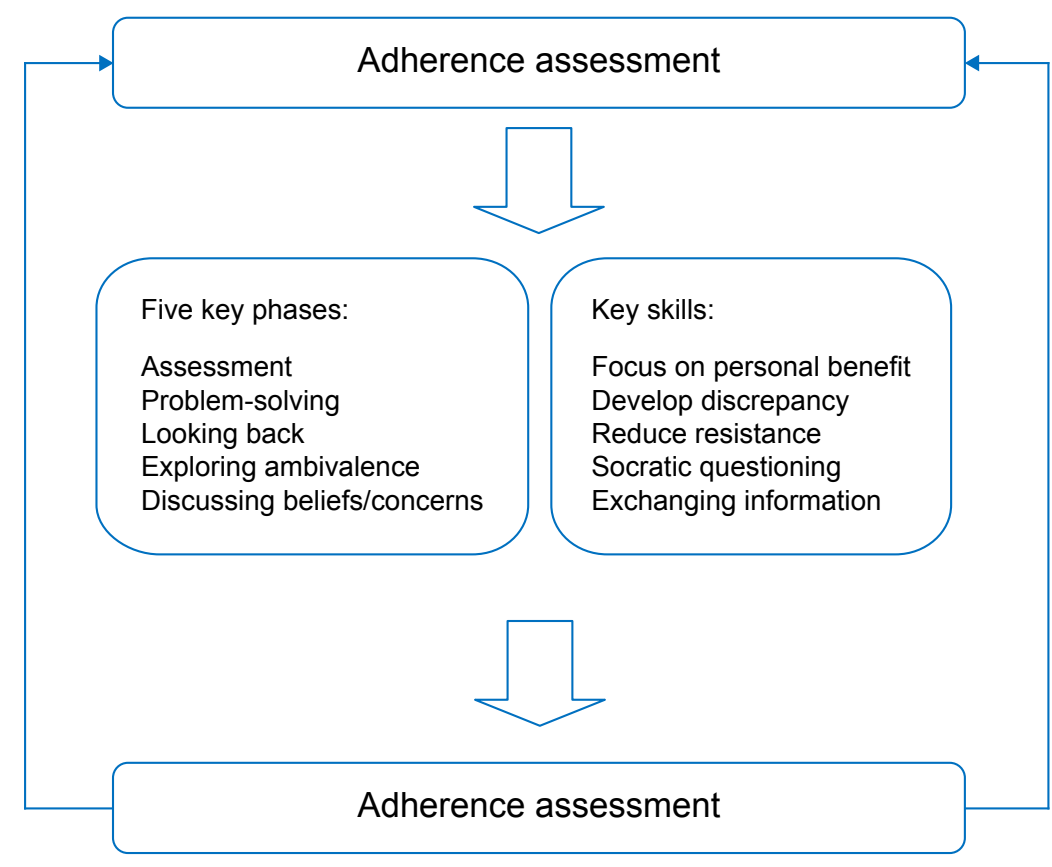

Figure I Adherence therapy components and skills. 


\section{Data analysis}

Thematic analysis ${ }^{10}$ was used according to the phases described in the following sections.

\section{Initial code generation}

Meaning from the data was used to generate codes that formed the basis of repeated patterns (subthemes). Codes were given definitions of their use/misuse and these were redefined to accommodate similar text segments.

\section{Searching for themes}

The emphasis was on developing themes encompassing related codes. Codes were arranged into plausible subthemes. Relevant data extracts were then collated for each subtheme. This phase ended with a collection of candidate subthemes housing all codes and related extracts.

\section{Revising the themes}

This involved two stages: in the first, DJD reviewed the collated extracts from each subtheme to ensure they followed a logical pattern; in the second, a similar process was involved, but in relation to the data set. Specifically, DJD re-read the data set to ensure the generated subthemes were consistent with the original transcripts.

\section{Defining and naming themes}

Here broader themes were developed and defined. Short theme names were generated which portrayed enough information to understand the content.

\section{Quality assurance}

A second qualitative researcher (RH), naïve to PD and AT, reviewed the transcripts independently. RH coded transcripts using the method described above. Despite generating different code names, the meaning of each code was consistent between DJD and RH. Code names were discussed between the coders and the most appropriate was agreed.

\section{Results}

Baseline demographic and clinical characteristics are presented in Table 1. All patients were white Caucasians and retired (except for patient 10 who did not work due to PD). Seven patients were female and the mean ( \pm standard deviation) age was $69.1 \pm 10.2$ years. The mean time since diagnosis was $6.6 \pm 4.5$ years. The Hoehn and Yahr score (a measure of disease severity) ranged from 0 (asymptomatic) to 4 (severe disability), with a median of 2.5 (interquartile range [IQR] 2). The median Montreal Cognitive Assessment Scale score was 26.5 (IQR 3), where $\leq 26 / 30$ represents mild cognitive impairment. Using the Hospital Anxiety and Depression Scale, the median score was 6 (IQR 5) and 5.5 (IQR 4) respectively ( $<8$ represents no symptoms). Patients were taking at least one levodopa preparation. Six spouse/carers were interviewed. Interviews lasted a mean of 30 minutes. In total, 175 codes were generated. These formed eleven subthemes that were grouped under three main themes, ie, perceptions prior to AT, positive effects of $\mathrm{AT}$, and attributes of AT (Table 2).

\section{Perceptions prior to AT}

\section{Poor understanding of PD and medication}

Most participants described having poor knowledge of PD prior to receiving AT. Most attributed this to a lack of previous explanation and/or opportunity to be informed in a meaningful way:

"The nature of the disease, nobody had ever explained that. I know the effect it has on me, but nobody explained it." (Participant 1)

Table I Baseline characteristics of interview participants

\begin{tabular}{|c|c|c|c|c|c|c|c|c|c|c|}
\hline \multirow[t]{2}{*}{ Participant } & \multirow{2}{*}{$\begin{array}{l}\text { Age, } \\
\text { years }\end{array}$} & \multirow[t]{2}{*}{ Sex } & \multirow[t]{2}{*}{ H\&Y } & \multirow{2}{*}{$\begin{array}{l}\text { Duration of } \\
\text { PD (years) }\end{array}$} & \multirow[t]{2}{*}{ MoCA } & \multicolumn{2}{|l|}{ HADS } & \multirow{2}{*}{$\begin{array}{l}\text { LEDD } \\
\text { (mg) }\end{array}$} & \multirow{2}{*}{$\begin{array}{l}\text { PD } \\
\text { drugs }\end{array}$} & \multirow{2}{*}{$\begin{array}{l}\text { Daily } \\
\text { doses }\end{array}$} \\
\hline & & & & & & Anxiety & Depression & & & \\
\hline I & 56 & Male & 3 & 7 & 25 & 6 & 11 & 640 & I & 4 \\
\hline 2 & 69 & Male & 2 & 7 & 28 & 6 & 3 & 740 & 2 & 7 \\
\hline 3 & 72 & Female & 1 & 2 & 18 & 10 & 6 & 1,038 & 2 & 4 \\
\hline 4 & 63 & Male & 3 & 4 & 27 & 5 & 2 & $\mathrm{I}, 758$ & 4 & 12 \\
\hline 5 & 71 & Female & 3 & 14 & 26 & 4 & 5 & 2,319 & 5 & 18 \\
\hline 6 & 68 & Female & 1 & 6 & 30 & 4 & 3 & 247.5 & 2 & 4 \\
\hline 7 & 72 & Female & 4 & 14 & 25 & 9 & 7 & 900 & 3 & 9 \\
\hline 8 & 87 & Female & 0 & 2 & 24 & 3 & I & 187.5 & I & 3 \\
\hline 9 & 80 & Female & 3 & 2 & 28 & 8 & 7 & 312.5 & 2 & 5 \\
\hline 10 & 53 & Female & 1 & 8 & 27 & 13 & 10 & 480 & 3 & 13 \\
\hline
\end{tabular}

Abbreviations: H\&Y, Hoehn and Yahr; MoCA, Montreal Cognitive Assessment Scale; HADS, Hospital Anxiety and Depression Scale; LEDD, levodopa equivalent daily doses; PD, Parkinson's disease. 
Table 2 Themes generated by thematic analysis

\begin{tabular}{|c|c|c|}
\hline Theme & Subtheme & $\begin{array}{l}\text { PD patients } \\
\text { (n) }\end{array}$ \\
\hline \multirow[t]{3}{*}{$\begin{array}{l}\text { Perceptions prior } \\
\text { to adherence } \\
\text { therapy }\end{array}$} & $\begin{array}{l}\text { Poor knowledge and } \\
\text { understanding of PD and } \\
\text { medications }\end{array}$ & 9 \\
\hline & Low mood/confidence & 5 \\
\hline & Decreased support/isolation & 5 \\
\hline \multirow{6}{*}{$\begin{array}{l}\text { Positive effects of } \\
\text { adherence therapy }\end{array}$} & Increased acceptance & 5 \\
\hline & Increased self-awareness & 5 \\
\hline & Increased confidence & 4 \\
\hline & $\begin{array}{l}\text { Increased knowledge/ } \\
\text { understanding of PD/ } \\
\text { medications }\end{array}$ & 10 \\
\hline & $\begin{array}{l}\text { Increased control/self- } \\
\text { discipline }\end{array}$ & 6 \\
\hline & Improved relationships & 4 \\
\hline \multirow{10}{*}{$\begin{array}{l}\text { Attributes of } \\
\text { adherence therapy }\end{array}$} & Therapy attributes & \\
\hline & $\begin{array}{l}\text { Flexibility, continuity, and } \\
\text { timing }\end{array}$ & 6 \\
\hline & Involved spouse & 3 \\
\hline & $\begin{array}{l}\text { Face-to-face in home } \\
\text { environment }\end{array}$ & 10 \\
\hline & Time to talk/openness & 8 \\
\hline & Therapist attributes & \\
\hline & Specialist knowledge & 10 \\
\hline & $\begin{array}{l}\text { Understanding and } \\
\text { interest }\end{array}$ & 6 \\
\hline & Equal relationship & 7 \\
\hline & Easy to understand & 5 \\
\hline
\end{tabular}

Abbreviation: PD, Parkinson's disease.

The lack of understanding was not specific to PD. Similarly, participants described how poor knowledge specific to medication use was also problematic:

"Before I would pop a pill and not understand why. Now I understand the peaks and troughs and why it's essential to maintain a steady concentration to keep equilibrium." (Participant 2)

\section{Low confidence/mood}

Half of the interviewees talked about their experiences of low mood, which they associated with PD. Low mood before commencing AT appeared to be related to lack of acceptance of $\mathrm{PD}$, which impacted negatively on medication use in some participants:

"I was very low when we met. When I filled my medication wallet up I hated my pills and myself. I felt guilty for having it (PD), like I'd let my family down. I felt resentful towards the pills." (Participant 10)

One spouse spoke of the devastating effect of PD on her husband's mood and confidence:
"After diagnosis he wanted to be alone. He became depressed. He wanted me to help him end it. He became non-compliant and less confident, not just with medication." (Spouse of participant 1)

\section{Decreased support/increased isolation}

Half of the patients described feeling isolated from people before AT. This feeling of isolation had a detrimental impact on daily life:

"Although you see the doctor, you're still living it alone inside. Before this (AT), I felt isolated and lonely living with $\mathrm{PD}$, even though my husband is here." (Participant 5)

Additionally, people reported a lack of professional support and felt they were left alone to face their disease:

"We didn't know where to turn or about what was coming.

We felt we were the only people facing this." (Spouse of participant 1)

\section{Positive effects of AT}

Participants spoke of having increased acceptance of PD and the need for medication. This appeared to be related to acquiring greater knowledge of PD. Participants described how self-awareness, confidence in daily life, support, selfcontrol, relationships with others, self-discipline, and an ability to function and cope were all improved after experiencing AT.

\section{Increased acceptance}

Several patients spoke of an increased acceptance of PD. This appeared to be associated with a developed understanding and acceptance of the indication for medication:

"Before I was in denial. I tried to ignore Parkinson's and the pills. Now my relationship with medication has improved as I'm no longer scared.” (Participant 10)

Some participants described how their new perspective of life with PD helped them to re-evaluate their attitudes toward medication:

"I've got to take more control of the medication. Had you not come I would still be in the same situation, ambivalent to medicines. Talking about it has somehow changed me." (Participant 5)

Alongside the increased acceptance of $\mathrm{PD}$, some patients spoke of how they no longer felt the need to hide their condition from others: 
'I'm not afraid to say I'm disabled. Before, I wouldn't even go outside. I'm better at explaining what I've got now." (Participant 1)

\section{Increased self-awareness}

Some participants described how "going off” was not thought to be related to suboptimal medication management. However, increased self-awareness of symptom control seemed to result from the enhanced understanding gained during the AT process:

"Before I was constantly eating to get some energy. Now I realize the sinking feeling is the Parkinson's. I am going off. Having the medicines more strictly, I haven't felt it as much." (Participant 3)

\section{Increased confidence}

Participants spoke of how their experience of AT had improved their perceptions of symptom control, allowing them to feel more confident in their ability to manage life with PD:

"Once I was taking my meds as we agreed I felt a huge difference. The length of freezing was less. I felt more confident to go outside. I went for a coffee alone, it felt great. I haven't done that for years." (Participant 1)

Some patients described how their increased confidence resulted in greater social participation:

“It's helped me socially. Before we met I wouldn't tell anyone. Now I don't mind talking to strangers about it (PD)." (Participant 2)

The spouse/carers of some patients reported how patients started to encourage medication adherence in others:

"He is now promoting what you've said, telling people how it's helping. He remembers the conversations and is now talking to others." (Spouse of participant 3)

\section{Increased knowledge of medication}

Participants spoke of how improved knowledge enabled them to appreciate the relevance of medication, such as the importance of correct time interval dosing in relation to their own symptom fluctuations:

"I've learnt about peaks and troughs regarding the medication and why it's important to take your medicine at certain times. I've learnt that in some respects I am governed by the clock." (Participant 2)
Some patients appeared to link their increased knowledge of PD medication to their improved self-awareness of symptoms:

"The peaks and troughs diagram was one of the most fascinating explanations. It was very powerful for me. I realize now that I am dipping, falling, so it spurs me to take the medication correctly." (Participant 3)

\section{Increased control/self-discipline}

Several participants discussed how their experience of AT increased their self-control/discipline. Participants felt that they had become stricter with themselves regarding their medication use, describing a sense of increased power and ability to cope:

"The discussion made me strict with myself. I think it (AT) made me think about things, rather than you telling me what I must do.” (Participant 6)

Some described how problem-solving strategies, identified collaboratively through shared decision-making, helped them to develop a sense of control over medication use:

"Now I sometimes remember the pills before the alarm gets a chance to remind me." (Participant 8)

\section{Improved relationships}

Participants reported how AT helped improve their relationships because of their increased sense of symptom control that they associated with feeling more confident:

"When I was non-compliant I convinced myself I couldn't do anything. Then, for the first time in years, I cooked my own dinner and the wife's too. She cried when she saw what I'd managed." (Participant 1)

Some participants spoke of how family members, including children, had noticed a difference in their ability to be more active and participatory:

"My granddaughter would come round and whereas I'd say sit there, we were going out to the park. I was doing more and she noticed." (Participant 4)

\section{Attributes of AT}

All patients felt their success resulted from the flexibility of the topics discussed and the method in which they were introduced. The inclusion of spouse/carers was helpful, but for varied reasons. All participants described how the collaborative, participatory, and face-to-face nature of AT was 
essential. The honesty and openness encouraged during the patient-professional interaction appeared to be paramount.

\section{Continuity and timing}

Participants praised the continuity of sessions with the same therapist. Some patients thought the sessions could have been longer to facilitate greater in-depth discussion:

"They were too short. It hardly seemed to start and then it was gone. I like how we started where we left off." (Participant 2)

\section{Involvement of spouse}

The presence of a spouse/carer appeared helpful, particularly where they had an active role in management of medication:

"There was a lot for me as the carer because you opened my eyes to many things which I didn't think were important." (Spouse of participant 7)

\section{In the home environment}

Most participants discussed how the delivery of AT face-toface in their own homes was essential. All spoke of how they felt other forms of delivery would not be as effective:

"The way it (AT) was presented made a hell of an impact.

You can't judge someone and their reactions over the phone." (Participant 2)

\section{Specialist knowledge}

In addition to the AT program, interviewees described how the characteristics of the therapist were vitally important, such as the possession of specialist knowledge:

"Because you had an understanding of PD I was halfway there. There were so many issues I had that we spoke about. I've not been able to do that with others." (Participant 10)

\section{Equal relationships}

Several participants spoke of how honesty and a nonjudgmental approach were key for encouraging open dialogue:

"It was welcoming not having to justify some of my actions. I felt I could say anything without you judging." (Participant 2)

Several participants also discussed how building a rapport with the therapist was paramount for gaining the trust required to facilitate honest discussion:
"I felt comfortable telling you my fears. I was able to say the simplest things and you put me at ease." (Participant 9)

\section{Discussion}

We explored the experiences of ten patients with PD and six spouses/carers who received a 7-week program of AT as part of a clinical trial. ${ }^{6}$ Thematic analysis generated three themes, ie, perceptions prior to AT, positive effects of AT, and attributes of AT.

\section{Perceptions prior to AT}

Most discussed their experiences prior to AT, referring to their poor understanding of PD and its treatments. Low mood/confidence and feeling isolated were also often reported. In many chronic conditions, people can become expert at symptom management. ${ }^{11}$ Medication adherence is therefore assumed in those with greater disease duration. Despite this, greater non-adherence is associated with longer disease duration in PD. ${ }^{2}$ Findings have shown that patients' understanding of PD medication is often not sufficient to manage the disease, especially concerning the importance of dose timing. ${ }^{12}$ Given that our participants reported poor knowledge of treatment prior to AT, our findings suggest the expert patient concept should not be presumed in PD.

Low mood/depression appeared to be associated with a lack of acceptance of PD. This subsequently impacted on adherence. It is known that depression is associated with poor medication adherence in chronic conditions. ${ }^{13}$ Depression is the factor most strongly associated with non-adherence in PD. ${ }^{2}$ It is therefore not surprising that low mood was reported, especially as research suggests depression is prevalent in $40 \%$ of people with PD. ${ }^{14}$ Low confidence was evident in our participants. As confidence can be associated with mood, this was not unexpected; low confidence in one's ability to cope (low self-efficacy) is common in chronic conditions. ${ }^{13}$ Researchers have shown interventions aimed at enhancing self-efficacy may be beneficial for improving self-management behaviors. ${ }^{15}$ This may include treatment adherence. Therefore, given that low confidence/mood are related and can affect medication adherence and general participation in life, this may explain why patients reported this as being significant prior to AT. Isolation and lack of support were also reported. This may suggest that current service provision, such as access to PD nurse specialists, may not be wholly addressing patients' needs.

\section{Positive effects of AT}

Participants reported how AT enabled them to appreciate the need for correct dose timing and to develop greater 
self-awareness. Poor self-awareness of symptoms is documented in PD. ${ }^{16,17}$ The fact that this improved may suggest that discussing medication use in relation to problems identified by patients provides greater meaning because it is personally relevant. This may account, at least in part, for the improved adherence behaviors observed in our study. ${ }^{6}$

Greater self-discipline to manage medication was also described, suggesting that AT not only improves adherence but also encourages patients to take control. Some described adapting problem-solving strategies, whilst others used their greater understanding to better plan drug dosing. This suggests that, after experiencing AT, patients may be more confident and competent to self-manage, which could improve adherence behaviors.

Several patients reported improved acceptance of PD and greater confidence in daily life. The linear mechanism of AT proposes that improving attitudes/beliefs about treatment, exchanging information, and assisting in problem-solving enhances medication adherence. These in turn improve clinical outcomes. ${ }^{8,18}$ Because improving adherence/quality of life was our aim, it is unlikely that acceptance and confidence improved as a result of enhanced adherence. Furthermore, as acceptance and confidence to cope (self-efficacy) are important for optimizing quality of life, it is possible that our reported improvements may result from other mechanistic pathways.

For example, whilst the linear mechanism may explain findings in hypertension, ${ }^{19}$ improvements in acceptance and confidence in PD may suggest that quality of life can be enhanced without a requisite improvement in adherence. As with the linear model, the pathways are likely to commence with identification of unique reasons for nonadherence. This may include a lack of acceptance of PD and/ or underlying symptoms of anxiety/depression. However, unlike the linear model, where addressing such factors leads directly to improved adherence, addressing poor acceptance of PD and exploring factors for non-adherence may offer alternative pathways by first improving one's confidence to cope with PD (ie, self-efficacy). This notion is consistent with reports of a positive correlation between self-efficacy and quality of life in other chronic conditions. ${ }^{20}$ Enhanced self-efficacy may impact positively on quality of life, which may lead to improved adherence behaviors. Therefore, whilst enhanced adherence may improve clinical outcomes, our findings indicate that AT is likely to be multidirectional in that people have unique pathways to improved outcomes (Figure 2). Although improving medication adherence was

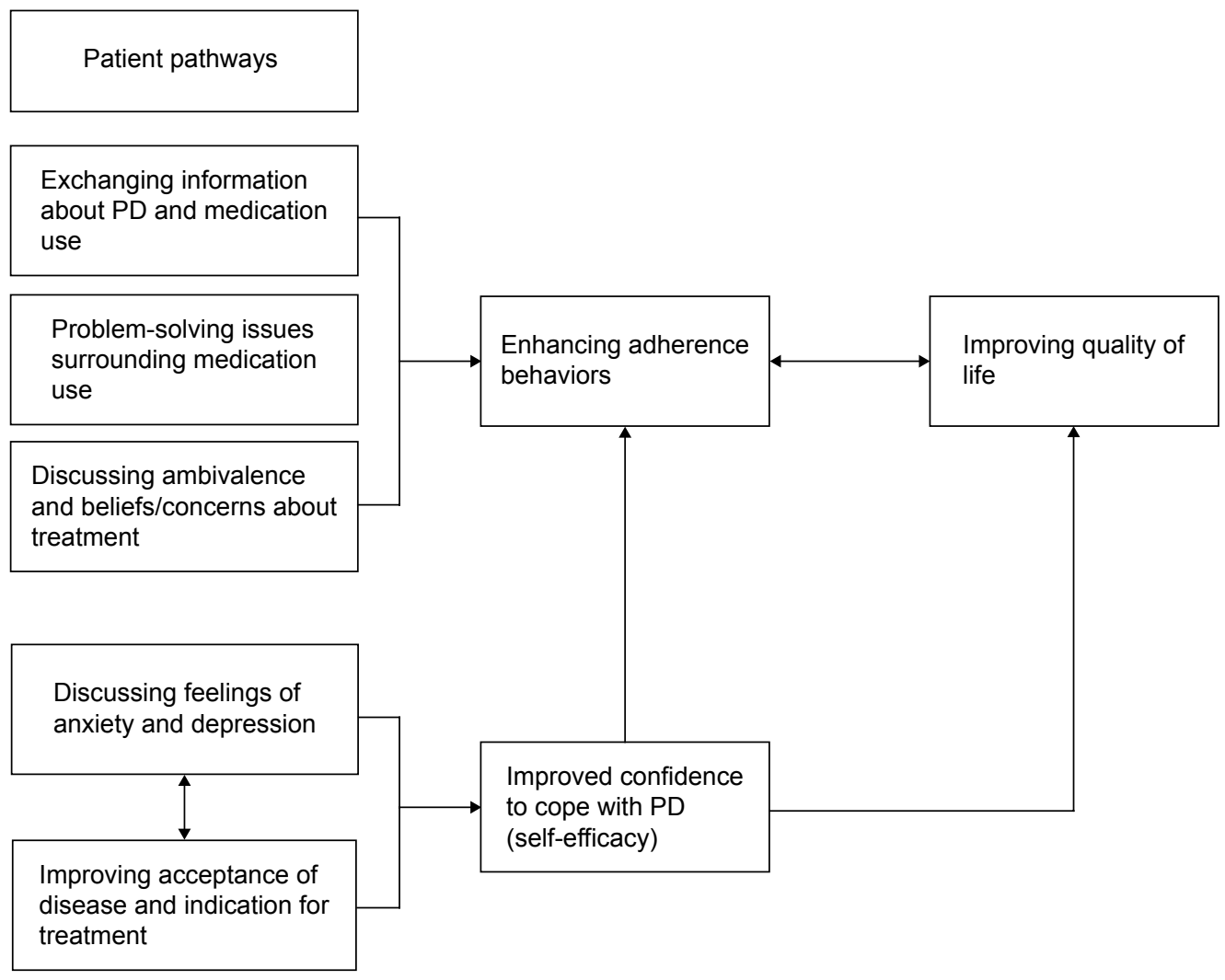

Figure 2 Multidirectional model of adherence therapy in Parkinson's disease. Abbreviation: PD, Parkinson's disease. 
our objective, the therapeutic effect of AT may be holistically beneficial in PD.

\section{Attributes of adherence therapy}

The topics discussed during AT, the flexibility in delivery, and the timing of sessions were viewed favorably. This is consistent with findings in hypertension. ${ }^{19}$ Patients felt it was vital that the same therapist delivered AT to ensure continuity. This should be recommended in future investigations. Gray et al showed that training mental health nurses to deliver AT resulted in significant improvements in medication adherence and symptoms in patients with schizophrenia. ${ }^{21}$ Therefore, researchers should investigate whether training multiple nurse/therapists to provide AT as a service in PD leads to consistently positive outcomes.

Most of our study participants reported that the duration of AT was sufficient. Some wished for more sessions whereas others required fewer. In the RCT, AT was administered weekly for 7 consecutive weeks. Our findings suggest that AT may be more beneficial when delivered according to individual patient need. This approach mirrors findings showing that medication adherence is enhanced when sufficient time is allocated for exploration of patient problems. ${ }^{22}$ Therefore, it may be that some require "top-up" sessions, whereas others need a shorter duration to achieve the same therapeutic effect.

Patients viewed the inclusion of spouse/carers favorably. This is not surprising because spouse/carers can be crucial for helping patients to manage PD medication and often feel overwhelmed and unable to cope. ${ }^{23}$ As their inclusion seemed important, it is essential that this be acknowledged in future investigations.

All participants described how face-to-face AT set in the home environment was essential. Feeling encouraged to discuss concerns openly was viewed by many as contributing to the acceptability of AT. Whilst patients favored the flexibility of AT, the current findings suggest that delivering AT outside the home environment is not likely to be as effective. Home delivery of AT may offer several benefits. Firstly, problem-solving is likely to be more easily facilitated due to familiarity of environment, particularly where cognitive impairment is evident. Secondly, patients may feel more at ease to discuss topics that would normally make them anxious. Thirdly, unlike clinical environments, where patient-professional interactions are often directed by professionals, home delivery of AT may mean that patients perceive the power dynamic to shift. This may explain why many participants felt comfortable talking openly in a way they might not have done in the clinic. Alhalaiqa et al ${ }^{19}$ showed a significant improvement in adherence and blood pressure in patients with hypertension who received AT either at home or in an outpatient department. Although patients in our RCT valued being at home, this finding proposes that AT may be effective when delivered in clinical settings. From an economic perspective, researchers should investigate the efficacy of AT in patients with PD when delivered via alternative means.

\section{Strengths and limitations}

This evaluation of AT in PD has several strengths. Firstly, all participants were interviewed within 1 week of completing AT, so their recollection would have been maximized. Secondly, this study is the first to evaluate experiences of receiving an adherence-promoting intervention in PD. Finally, the use of a secondary qualitative researcher naïve to AT and PD provided quality assurance to the analysis process.

There are some limitations to this research. Firstly, only ten PD patients were interviewed. As our intention was to assess the acceptability of AT from the perspective of patients, the trial steering committee decided that a purposely selected sample would ensure we ascertained the views and experiences of a wider demographic. For this reason, despite the small sample, we feel it is unlikely that the views of the other RCT participants would differ substantially. Secondly, symptoms of anxiety/depression were assessed in our RCT, but at baseline only. However, self-efficacy was not assessed. As the interview findings suggest that enhancing self-efficacy and exploring symptoms of anxiety/depression may be beneficial for improving confidence to cope with $\mathrm{PD}$, it is essential that these be assessed as outcome measures in the future. Thirdly, as only some of our interviewees were cognitively impaired, it is possible that AT may be less beneficial in these patients. AT for cognitively impaired patients requires specific investigation. Finally, an independent interviewer would be desirable in future evaluations of AT.

\section{Conclusion}

We evaluated the acceptability of AT in PD. Three themes and eleven subthemes were identified and enhanced our understanding of AT. A new mechanism of action was proposed, which future research should seek to confirm. A recent priority setting partnership survey identified a need to better manage some of the symptoms of PD. ${ }^{24}$ However, many such symptoms are sensitive to levodopa. ${ }^{25-27}$ Improvement in adherence is therefore essential. The findings of this qualitative evaluation provide a deeper understanding of the 
potential underlying mechanism of AT. The proposed new model should allow researchers and clinicians to modify the delivery of AT by acknowledging the various pathways to improved outcomes.

\section{Acknowledgments}

We wish to thank all participants for their contribution to this work. We thank Fiona Reading, Michelle Green, Rachael Rendell, Terri Johns, Bronwen Roper, and the lay members of the trial steering committee, ie, Garth Ravenhill and Philip Harrison, for their support. We give special thanks to Debbie Davey for her invaluable efforts as data clerk. This research was funded by a University of East Anglia PhD studentship.

\section{Disclosure}

RG originally described AT and has received fees for providing AT training. The authors report no other conflicts of interest in this work.

\section{References}

1. Grosset D, Antonini A, Canesi M, et al. Adherence to antiparkinson medication in a multicenter European study. Mov Disord. 2009;24: 826-832.

2. Daley DJ, Myint PK, Gray RJ, Deane KH. Systematic review on factors associated with medication non-adherence in Parkinson's disease. Parkinsonism Relat Disord. 2012;18:1053-1061.

3. Haynes RB, Ackloo E, Sahota N, McDonald HP, Yao X. Interventions for enhancing medication adherence. Cochrane Database Syst Rev. 2008;2:CD000011.

4. Kripalani S, Yao X, Haynes RB. Interventions to enhance medication adherence in chronic medical conditions: a systematic review. Arch Intern Med. 2007;167:540-549.

5. Daley D, Deane K, Gray R, et al. The use of carer assisted adherence therapy for people with Parkinson's disease and their carers (CAATPARK): study protocol for a randomised controlled trial. Trials. 2011; 12:251.

6. Daley DJ, Deane KH, Gray RJ, et al. Adherence therapy improves medication adherence and quality of life in people with Parkinson's disease: a randomised controlled trial. Int J Clin Pract. 2014;68:963-971.

7. Gray R, White J, Schulz M, Abderhalden C. Enhancing medication adherence in people with schizophrenia: an international programme of research. Int J Ment Health Nurs. 2010;19:36-44.

8. Gray R, Leese M, Bindman J, et al. Adherence therapy for people with schizophrenia. European multicentre randomised controlled trial. $\mathrm{Br} J$ Psychiatry. 2006;189:508-514.

9. Gray R. Adherence therapy: working together to improve health. A treatment manual for healthcare workers. University of East Anglia, 2011. Available from: http://www.academia.edu/2436503/Adherence_ therapy_manual. Accessed June 12, 2015.
10. Braun V, Clarke V. Using thematic analysis in psychology. Qual Res Psychol. 2006;3:77-101.

11. Badcott D. The expert patient: valid recognition or false hope? Med Health Care Philos. 2005;8:173-178.

12. Drey N, McKeown E, Kelly D, Gould D. Adherence to antiparkinsonian medication: an in-depth qualitative study. Int J Nurs Stud. 2012;49: 863-871.

13. Dimatteo MR, Lepper HS, Croghan TW. Depression is a risk factor for noncompliance with medical treatment: meta-analysis of the effects of anxiety and depression on patient adherence. Arch Intern Med. 2000; 160:2101-2107.

14. Shiba M, Bower JH, Maraganore DM, et al. Anxiety disorders and depressive disorders preceding Parkinson's disease: a case-control study. Mov Disord. 2000;15:669-677.

15. Farrell K, Wicks MN, Martin JC. Chronic disease self-management improved with enhanced self-efficacy. Clin Nurs Res. 2004;13: 289-308.

16. Vitale C, Pellecchia MT, Grossi D, et al. Unawareness of dyskinesias in Parkinson's and Huntington's diseases. Neurol Sci. 2001;22:105-106.

17. Sitek EJ, Slawek J, Wieczorek D. [Self-awareness of deficits in Huntington's and Parkinson's disease]. Psychiatr Pol. 2008;42:393-403. Polish.

18. Horne R, Weinman J. Patients' beliefs about prescribed medicines and their role in adherence to treatment in chronic physical illness. J Psychosom Res. 1999;47:555-567.

19. Alhalaiqa F, Deane KH, Nawafleh AH, Clark A, Gray R. Adherence therapy for medication non-compliant patients with hypertension: a randomised controlled trial. J Hum Hypertens. 2011;26:117-126.

20. Arnold R, Ranchor AV, Dejongste MJ, et al. The relationship between self-efficacy and self-reported physical functioning in chronic obstructive pulmonary disease and chronic heart failure. Behav Med. 2005;31: $107-115$.

21. Gray R, Wykes T, Edmonds M, Leese M, Gournay K. Effect of a medication management training package for nurses on clinical outcomes for patients with schizophrenia: cluster randomised controlled trial. Br J Psychiatry. 2004;185:157-162.

22. Sookaneknun P, Richards RM, Sanguansermsri J, Teerasut C. Pharmacist involvement in primary care improves hypertensive patient clinical outcomes. Ann Pharmacother. 2004;38:2023-2028.

23. A'Campo LE, Spliethoff-Kamminga NG, Macht M; EduPark Consortium, Roos RA. Caregiver education in Parkinson's disease: formative evaluation of a standardized program in seven European countries. Qual Life Res. 2010;19:55-64.

24. Deane KH, Flaherty H, Daley DJ, et al. Priority setting partnership to identify the top 10 research priorities in Parkinson's disease. BMJ Open. 2014;4(12):e006434.

25. Schapira AH, Emre M, Jenner P, Poewe W. Levodopa in the treatment of Parkinson's disease. Eur J Neurol. 2009;16:982-989.

26. Molloy SA, Rowan EN, O'Brien JT. Effect of levodopa on cognitive function in Parkinson's disease with and without dementia and dementia with Lewy bodies. J Neurol Neurosurg Psychiatry. 2006;77: $1323-1328$.

27. Kulisevsky J, Garcia-Sanchez C, Berthier ML. Chronic effects of dopaminergic replacement on cognitive function in Parkinson's disease: a two-year follow-up study of previously untreated patients. Mov Disord. 2000;15:613-626. 


\section{Supplementary material}

What did you find most helpful and least helpful?

When you started the programme, what were your expectations?

What happened that you did and didn't like?

What did you think about session duration/environment and input of your carer?

What have you learnt? Has it changed the way you view your medication?

How could the therapy be improved, if at all?

Would you recommend the therapy?

Between the sessions did you think about what was talked about? How did it make you feel?

How have the sessions, if at all, made you think about your Parkinson's disease?

Has the way you perceive your medication changed? How?

Figure SI Interview question prompts.

\section{Publish your work in this journal}

Patient Preference and Adherence is an international, peer-reviewed, open access journal that focuses on the growing importance of patient preference and adherence throughout the therapeutic continuum. Patient satisfaction, acceptability, quality of life, compliance, persistence and their role in developing new therapeutic modalities and compounds to optimize clinical outcomes for existing disease states are major areas of interest for the journal. This journal has been accepted for indexing on PubMed Central. The manuscript management system is completely online and includes a very quick and fair peer-review system, which is all easy to use. Visit http://www. dovepress.com/testimonials.php to read real quotes from published authors.

Submit your manuscript here: http://www.dovepress.com/patient-preference-and-adherence-journal 